\title{
Formulation-Development and Evaluation of Polysorbate- Phospholipid Mixed Micelles of Piperine Loaded with Azithromycin
}

\author{
Karuna Kumari 1 (D), Promod Kumar Sharma ${ }^{1}$, Rishabha Malviya ${ }^{1, *(D)}$ \\ 1 Department of Pharmacy, School of Medical and Allied Sciences, Galgotias University, Plot No 17 A, Yamuna \\ Expressway, Greater Noida, U.P., India \\ * Correspondence: rishabhamalviya19@gmail.com; rishabha.malviya@galgotiasuniversity.edu.in;
}

Scopus Author ID 36542724200

Received: 7.04.2020; Revised: 28.04.2020; Accepted: 30.04.2020; Published: 3.05.2020

\begin{abstract}
The overall goal of this paper was to develop polysorbate-phospholipid micelles of piperine loaded with azithromycin, and to study the effect and mechanisms enhancing the oral bioavailability of piperine and also to inhibit the bacterial growth. For the preparation of polysorbate-phospholipidpiperine mixed micelles loaded with a drug, polysorbate and phospholipid were optimized. Polysorbate concentration at $5.5 \% \mathrm{w} / \mathrm{v}$ showed the maximum solubility of piperine which was just similar to $5.0 \%$ w/v CMC value so, from such studies, it was confirmed that optimum concentration of polysorbate 80 required for maximum solubilization of piperine was $5.5 \% \mathrm{w} / \mathrm{v}$. The maximum CMC of polysorbate 80 and phospholipid was found in batch F3 i.e. 62.4414 and 83.1122, respectively. Based on the optimization of phospholipid and polysorbate 80 , three final batches were selected as the best batch i.e. F2, F3, and F4 (1:10:4, 1:15:4 and 1:20:4, respectively) for final formulation. In the formulation, maximum solubility was found in batch F3 i.e. $11.3057 \mathrm{mg} / \mathrm{ml}$. The size of the nanoformulations was found to be $0.3396 \mathrm{r}$.nm by using zeta analyzer. The drug release was determined in $0.1 \mathrm{~N} \mathrm{HCl}$ at 5, 10, 15, 30 and $60 \mathrm{~min}$. Further, $7.4 \mathrm{pH}$ phosphate was added and release was determined at 30, 60, 120, 180 and 240 min. It was noted that formulation F3 has maximum drug content and F1 was found as maximum entrapment efficiency. The maximum drug release was found in the formulation F3. The approach of using phospholipid nanoformulations loaded with azithromycin showed antibacterial activity in the nutrient agar plate. These formulations prevent the visual growth of bacteria. It was shown that the maximum zone of inhibition was found at the concentration of $100 \mathrm{mg} / \mathrm{ml}$. The MIC endpoint at the lowest concentration of formulation at which there is minimum visual growth around the dice was found to be $50 \mathrm{mg} / \mathrm{ml}$.
\end{abstract}

Keywords: drug delivery; nanoformulation; phospholipid; polysorbate 80; piperine; azythroycin, micelles.

(c) 2020 by the authors. This article is an open access article distributed under the terms and conditions of the Creative Commons Attribution (CC BY) license (https://creativecommons.org/licenses/by/4.0/).

\section{Introduction}

Nanoformulations of Pharmaceuticals have attracted the interest of many researchers for drug delivery applications. These nano-formulations enhance the properties of conventional drugs and are specific to the targeted delivery site. Dendrimers, liposomes, polymeric nanoparticles, nanoemulsions and micelles are some of the nanoformulations that are gaining importance in the Pharmaceutical industry for enhanced drug formulation. Many methods are available for the preparation of nanoformulations to deliver drugs in a biological system. The selection of synthesis methods depends on the shape and size of particulate formulation, 
biochemical properties of the drug, and the targeted site. The most rising branch in Pharmaceutical sciences known as "Pharmaceutical nanotechnology" presents new opportunities, tools and scope, which are expected to have important applications in disease diagnostics and therapeutics. Recently nanopharmaceuticals reveals the enormous potential in drug delivery as the carrier for spatial and temporal delivery of bioactive and diagnostics. Delivering remedial compounds to the targeted site is a major problem in the treatment of many diseases. Conventional utilization of drugs is characterized by poor biodistribution, undesirable side effects, limited effectiveness, and lack of selectivity [1]. Targeting of the drug to the respective receptor tissues is one of the challenging tasks in the field of formulation development as the presence of barriers in the form of enzymatic proteins has been estimated to cause retardation or resistance to various drugs. The human P-glycoprotein is one of the multidrug resistance proteins which prevent the accumulation of the drug in the brain, heart, placenta, ovaries and testes tissues by extruding the drug molecules into the urine, bile and intestinal lumen [2]. It belongs to a subfamily of ATP-binding cassette transporters and is generally recognized as a surface glycoprotein. In human tissues, P-gp is mainly concentrated in the liver, pancreas, jejunum, kidney and colon [3,4]. This membrane-bound protein is an energy-dependent efflux transporter that is mainly provided by the hydrolysis of ATP [5]. The unique characteristics of the P-gp have been reported to be responsible for the movement of drugs in or in the opposite direction thus affecting overall drug permeability and bioavailability [6]. Azithromycin inhibits some Gram-positive bacteria as well as some Gram-negative bacteria. It binds to the $50 \mathrm{~S}$ subunit of the bacterial ribosome, thus inhibiting the translation of mRNA [7]. Along with polysorbate, the use of natural and synthetic polymers especially phospholipids has proved its worth. Phospholipids as a carrier for anticancer drugs are very common but their inhibitory action over P-gp was also reported. Synthetic phospholipids especially 1,2-dioctanoyl-sn-glycero-3-phosphocholine (8:0 PC) and 1,2didecanoyl-sn-glycero-3-phosphocholine (10:0 PC) were used for determining their influence on the cellular transport of P-gp substrate rhodamine 123 (RH123) on Caco-2 cell layers. The approach of using lipid nano complex loaded with Azithromycin showed P-gp inhibition activity and even the activity was independent of the size of the nanoformulations. The mechanism of drug release from lipid nanoformulations in combination with intracellular P-gp inhibition ensured a higher anticancer drug concentration inside the cancer cells [8].

Bioenhancer activity of piperine was proposed including modulation of cell signal transduction, DNA receptor binding and inhibition of drug efflux pump. Piperine widely used in the pharmaceutical industry. Thus, the scope of formulation and development of polysorbate-phospholipid mixed micelles, loaded with a drug, proved to deliver active drug molecules to various tissues into the body where the entry of drugs as intact is restricted by Pglycoprotein enzymes [9, 10]. Scopes of nano complex are as follows: Preparation of formulation that inhibits drug-metabolizing enzymes and stimulates absorption by stimulating gut amino acid transporters; The efficacy of the drug is increase due to an increase in bioavailability; The formulation which mainly increases the absorption of the drug in the GIT, or inhibits enzymes responsible for drug metabolism. 


\section{Materials and Methods}

\subsection{Optimization of Polysorbate 80 concentration.}

Solubility enhancement being the demand in the situation would be possible by formulating complex particles dispersed in aqueous solution. The dissolution of hydrophobic particles in aqueous solution requires the addition of surfactant with high HLB value and in that case, polysorbate 80 with HLB value of 15 was chosen. So, the optimization of the concentration of polysorbate 80 by determining its CMC was observed. Based on CMC, the formulation and development of different batches of nano-complex particles dispersed in aqueous solution were performed for determining its solubility.

\subsection{Determination of CMC (Critical micelle concentration).}

The properties of an aqueous solution containing a surfactant in different concentration show a sudden change in surface tension, electrical conductivity, viscosity and absorption coefficient on achieving CMC. For the determination of CMC surface tension was also determined. Keeping such things in mind polysorbate 80 in different concentration starting from $1 \% \mathrm{w} / \mathrm{v}$ was added in the constant volume aqueous solution and surface tension at each concentration of added polysorbate 80 was determined consecutively.

\subsection{Formulation and development of placebo batches.}

The formulation was prepared using the solvent evaporation method (table 1). Piperine, phospholipid and cholesterol (1:10:2) dissolved in chloroform:methanol (2:1) solvent system. Tween 80 was admixed with an above organic solution at different concentrations (table 1) under constant magnetic stirring, thus forming a milky colloidal suspension. The organic solvent was then evaporated off with continuous addition of distilled water. The phospholipidpolysorbate colloidal formulations were purified from undissolved drug particles by centrifugation $(15,000 \mathrm{x})$ for 10 minutes at room temperature. The obtained supernatants were collected and the pellets resuspended in $10 \mathrm{ml}$ of buffer medium ( $\mathrm{pH}$ 7.2) and again centrifuged under the same conditions. The whole operation was repeated thrice and the final obtained supernatant was the final formulation.

Table 1. Composition of placebo batches for optimization of polysorbate 80 .

\begin{tabular}{|c|c|c|c|}
\hline $\begin{array}{c}\text { Formulation } \\
\text { Code }\end{array}$ & $\begin{array}{c}\text { Piperine + Soya PC + Cholesterol } \\
(1: 10: 2)(\% \mathrm{w} / \mathrm{v})\end{array}$ & $\begin{array}{l}\text { Distilled water } \\
(\mathrm{ml})\end{array}$ & Polysorbate $80(\%$ w/v $)$ \\
\hline $\mathrm{F}_{1}$ & 0.05 & 100 & 0.5 \\
\hline $\mathrm{F}_{2}$ & 0.05 & 100 & 1.0 \\
\hline $\mathrm{F}_{3}$ & 0.05 & 100 & 1.5 \\
\hline $\mathrm{F}_{4}$ & 0.05 & 100 & 2.0 \\
\hline $\mathrm{F}_{5}$ & 0.05 & 100 & 2.5 \\
\hline $\mathrm{F}_{6}$ & 0.05 & 100 & 3.0 \\
\hline $\mathrm{F}_{7}$ & 0.05 & 100 & 3.5 \\
\hline $\mathrm{F}_{8}$ & 0.05 & 100 & 4.0 \\
\hline $\mathrm{F}_{9}$ & 0.05 & 100 & 4.5 \\
\hline $\mathrm{F}_{10}$ & 0.05 & 100 & 5.0 \\
\hline $\mathrm{F}_{11}$ & 0.05 & 100 & 5.5 \\
\hline$F_{12}$ & 0.05 & 100 & 6.0 \\
\hline$F_{13}$ & 0.05 & 100 & 6.5 \\
\hline $\mathrm{F}_{14}$ & 0.05 & 100 & 7.0 \\
\hline$F_{15}$ & 0.05 & 100 & 7.5 \\
\hline$F_{16}$ & 0.05 & 100 & 8.0 \\
\hline $\mathrm{F}_{17}$ & 0.05 & 100 & 8.5 \\
\hline $\mathrm{F}_{18}$ & 0.05 & 100 & 9.0 \\
\hline \multicolumn{3}{|c|}{ https://biointerfaceresearch.com/ } & 6130 \\
\hline
\end{tabular}




\subsection{Solubility estimation.}

The final formulation containing 10mg of Piperine was pipette out $(1 \mathrm{ml})$ from each formulation batch and diluted upto $10 \mathrm{ml}$ of different buffer solutions $0.1 \mathrm{~N} \mathrm{HCL}(\mathrm{pH} 1.1$ ), $0.1 \mathrm{M}$ sodium phosphate $(\mathrm{pH} 3)$, citric acid and sodium phosphate ( $\mathrm{pH} 4.5$ ), $0.1 \mathrm{M}$ sodium phosphate buffer ( $\mathrm{pH} 7$ ) and $0.1 \mathrm{M}$ TRIS buffer ( $\mathrm{pH} \mathrm{9)}$ respectively. Finally, the effect of different range of $\mathrm{pH}$ on the solubility of Piperine among each formulation batch was determined by scanning samples through UV spectrophotometer at $342 \mathrm{~nm}$ with proper dilution.

\subsection{Optimization of Phospholipid concentration.}

The optimum concentration of cholesterol to be added into the vesicle formation is 30$50 \%$. The concentration of cholesterol also affects the efflux of the drug as it allows the filling of the pores present in the bilayers by abolishing the gel-liquid phase transition thus preventing the leakage of drug from the vesicles. This nature is considered favorable for sustained delivery. The optimization of phospholipid concentration in the formulation is mainly based on its functionality; being self-emulsifying property the CMC of phospholipid was determined and then some placebo formulations containing phospholipid in different concentrations were prepared and the optimum concentration of phospholipid was determined by solubility and entrapment efficiency estimation.

\subsection{Determination of CMC (Critical micelle concentration).}

Micellar delivery systems (less than 100nm) can be prepared for tissue penetration for a targeted delivery system. CMC is defined as the concentration of surfactant at which micelle formation starts. For the determination of CMC surface tension was also determined. Keeping such things in mind polysorbate 80 in different concentration starting from $1 \% \mathrm{w} / \mathrm{v}$ was added in the constant volume aqueous solution and surface tension at each concentration of added polysorbate 80 was determined consecutively.

\subsection{Formulation and development of Placebo batches.}

The phospholipid concentration was optimized by formulating five batches (table 2). The different compositions of Piperine, phospholipid and cholesterol were dissolved in chloroform:methanol (2:1) solvent system. Tween 80 was admixed with the above organic solution at different concentrations under constant magnetic stirring, thus forming a milky colloidal suspension. The organic solvent was then evaporated off with continuous addition of distilled water. The Phospholipid-Polysorbate colloidal formulations were purified from undissolved drug particles by centrifugation $(15,000 \mathrm{xg})$ for 10 minutes at room temperature. The obtained supernatants were collected and the pellets resuspended in a buffer medium and again centrifuged under the same conditions. The whole operation was repeated thrice and the final obtained supernatant was the final formulation.

\subsection{Solubility estimation.}

The final formulation containing 10mg of Piperine was pipetted out $(1 \mathrm{ml})$ from each formulation batch and diluted upto $10 \mathrm{ml}$ of buffer solutions $0.1 \mathrm{M}$ sodium phosphate $(\mathrm{pH} 3)$. 
The final determination of piperine concentration was determined by scanning samples through UV spectrophotometer at $342 \mathrm{~nm}$ with proper dilution.

Table 2. Composition of placebo batches for optimization of phospholipid.

\begin{tabular}{l|c|c|c}
\hline Formulation & $\begin{array}{c}\text { Piperine + Phospholipid } \\
\text { + Cholesterol }\end{array}$ & $\begin{array}{c}\text { Distilled } \\
\text { water }(\mathbf{m l})\end{array}$ & Polysorbate 80 $(\% \mathbf{w} / \mathbf{v})$ \\
\hline $\mathrm{F}_{1}$ & $1: 5: 1$ & 100 & 5.5 \\
\hline $\mathrm{F}_{2}$ & $1: 10: 2$ & 100 & 5.5 \\
\hline $\mathrm{F}_{3}$ & $1: 15: 3$ & 100 & 5.5 \\
\hline $\mathrm{F}_{4}$ & $1: 20: 4$ & 100 & 5.5 \\
\hline $\mathrm{F}_{5}$ & $1: 25: 5$ & 100 & 5.5 \\
\hline
\end{tabular}

\subsection{Entrapment Efficiency.}

The entrapment efficiency was determined by calculating the volume of the formulation containing $10 \mathrm{mg}$ of piperine as theoretical concentration. The calculated volume was then diluted upto $10 \mathrm{ml}$ of buffer solutions $0.1 \mathrm{M}$ sodium phosphate $(\mathrm{pH} 3)$. The final determination of piperine concentration was determined by scanning samples through UV spectrophotometer at $342 \mathrm{~nm}$ with proper dilution. The entrapment efficiency was then calculated using equation 1:

$$
\text { E. E } \%=\frac{\text { Observed concentration }}{\text { Theoretical concentration }} \times 100 \quad \text { equation } 1
$$

\subsection{Formulation and development of drug-loaded batches.}

The final formulation was prepared following a described solvent evaporation method (table 3). Drug (azithromycin), phospholipid, cholesterol (1:20:4) and piperine (10\% w/v) was dissolved in chloroform:methanol (2:1) solvent system. Tween 80 was admixed with the above organic solution at the concentration of $9 \mathrm{ml}$ under constant magnetic stirring, thus forming a milky colloidal suspension. The organic solvent was then evaporated off with continuous addition of distilled water. The Phospholipid-Polysorbate colloidal formulations were purified from undissolved drug particles by centrifugation for 10 minutes at room temperature. The obtained supernatants were collected and the pellets resuspended in $10 \mathrm{ml}$ of buffer medium (pH 7.2) and again centrifuged under the same conditions. The whole operation was repeated thrice and the final obtained supernatant was the final formulation.

Table 3. Formulation and development of drug-loaded batches.

\begin{tabular}{l|c|c|c}
\hline Formulation & $\begin{array}{c}\text { Drug:Phospholipil:Cholesterol and } \\
\text { piperine 10\% (w/v) i.e. } \mathbf{~ m g}\end{array}$ & $\begin{array}{c}\text { Distilled water } \\
(\mathbf{m l})\end{array}$ & $\begin{array}{c}\text { Polysorbate 80 (\%) } \\
\mathbf{w} / \mathbf{v})\end{array}$ \\
\hline $\mathrm{F}_{1}$ & $1: 10: 4$ & 100 & 5.5 \\
\hline $\mathrm{F}_{2}$ & $1: 15: 4$ & 100 & 5.5 \\
\hline $\mathrm{F}_{3}$ & $1: 20: 4$ & 100 & 5.5 \\
\hline
\end{tabular}

\subsection{Evaluation parameter.}

2.11.1. Particle size analysis.

The particle sizes of the nanoparticleswere determined by using a zeta analyzer or zeta sizer. $1 \%$ solution of theformulation was employed for the zeta analyzer. 


\subsubsection{Entrapment Efficiency (\%).}

For the calculation of \% entrapment efficiency, the absorbance of different formulations was analyzed and concentrations were calculated using the calibration plot of the drug. The $\%$ EE was calculated by using equation 2.

Entrapment Efficiency $(\%)=($ Total drug-Free drug/1000) $* 100 \quad$ equation 2

\subsubsection{Drug Content.}

The drug content was checked by a similar procedure as of the \% Entrapment efficiency. Drug content was calculated using equation 3.

Drug content $=$ Concentration $\mathrm{x}$ dilution factor

equation 3

\subsubsection{Drug Release (\%).}

Drug release $(\%)$ of the formulation was determined by using a rotating Basket of dissolution apparatus. The drug release was determined in $0.1 \mathrm{~N} \mathrm{HCl}$ at 5, 10, 15, 30 and 60 min. Further, $7.4 \mathrm{pH}$ phosphate was added and release was determined at 30, 60, 120, 180 and $240 \mathrm{~min} .5 \mathrm{ml}$ of the sample was withdrawn at a particular time interval. Samples were analyzed under $\mathrm{UV}$ at $231 \mathrm{~nm}$ of $0.1 \mathrm{~N} \mathrm{HCl}$ and at $233 \mathrm{~nm}$ of $\mathrm{pH} 7.4$ phosphate buffer. The \% drug release was calculated using equation 4 .

$$
\% \text { Drug release }=\frac{\text { Concentration formulation } \times \text { Dilution factor } \times \text { Bath volume }}{1000} \times 100 \quad \text { equation } 4
$$

\subsubsection{TEM.}

This technique involves freezing biological material quickly in vitreous ice and imaging at temperatures less than $-180^{\circ} \mathrm{C}$.

\subsubsection{Zeta size analysis.}

The particle sizes of the nanoformulations were determined by using zeta analyzer or zeta seizer. Solution $(1 \% \mathrm{v} / \mathrm{v})$ of the formulation was employed for the zeta analysis.

2.11.7. Preparation of nutrient agar medium (NAM).

Take nutrient agar from HiMedia Laboratories Pvt. Ltd. Suspend 14.0gm in 500ml of distilled water. Heat it to boil and dissolve the medium completely. It was sterilized by autoclaving at $15 \mathrm{Ibs}$ pressure $\left(121^{\circ} \mathrm{C}\right)$ for 15 minutes. After that, it was mixed well and poured into the sterilized Petri plates.

\subsubsection{Antibacterial activity.}

For the antibacterial activity of formulation, pour $25 \mathrm{ml}$ of culture medium onto each Petri plate of $90 \mathrm{~mm}$ in diameter to give an equal level of depth. Plates were prepared with an increasing concentration of formulation. The bacterial suspension (E. coli) was incubated onto the surface of the culture medium with the help of the inoculation loop. This procedure must be repeated at list twice onto the surface of the culture medium. Place the plates into a sterile laminar airflow cabinet. Formulation, loaded with different concentrations of drug was 
prepared. Dip sterilized disc into the formulation and again sterilized through hot air oven. After that place all discs into the center of the culture medium. Finally, incubate the plates in an inverted position at $35^{\circ} \mathrm{C}$ for $48 \mathrm{~h}$.

\section{Results and Discussion}

\subsection{Optimization of Polysorbate 80.}

$\mathrm{pH}$ based solubility profile of drug release from different formulation was determined as shown in table 4. Among different formulations, the maximum solubilized concentration was observed at $\mathrm{pH}$ 3. Similar was the condition when $\mathrm{pH}$ based solubility profile of the pure drug was determined as depicted in figure 1. The maximum solubility of pure drug and drug released from formulation at acidic $\mathrm{pH}$ could be correlated with the physiological gastric $\mathrm{pH}$. The $\mathrm{pH}$ based solubility profile also cleared that the drug is stable at all $\mathrm{pH}$ values shows maximum solubility at acidic $\mathrm{pH}$ while lower at basic $\mathrm{pH}$. The maximum solubility at acidic $\mathrm{pH}$ confirmed the weakly basic nature which was previously also confirmed by the $\mathrm{pKa}$ determination in preformulation studies. Similarly, the effect of tween 80 concentrations on the solubility of piperine at $\mathrm{pH}$ was determined as depicted in table 3 . Tween 80 concentration at $5.5 \% \mathrm{w} / \mathrm{v}$ showed the maximum solubility of piperine which was just similar to $5.0 \% \mathrm{w} / \mathrm{v} \mathrm{CMC}$ value so, from such studies, it was confirmed that optimum concentration of tween 80 required for maximum solubilization of piperine was $5.5 \% \mathrm{w} / \mathrm{v}$.

Table 4. $\mathrm{pH}$ dependant solubility of Polysorbate 80 .

\begin{tabular}{|c|c|c|c|c|c|c|c|c|}
\hline \multirow{2}{*}{ Formulation } & \multirow{2}{*}{$\begin{array}{c}\text { Tween } 80 \\
(\% \mathrm{w} / \mathrm{v})\end{array}$} & \multicolumn{7}{|c|}{ pH } \\
\hline & & 1.1 & 3 & 4.5 & 7 & 9 & \multirow{19}{*}{ 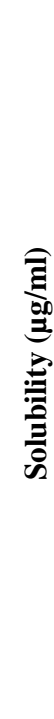 } & \\
\hline $\mathrm{F} 1$ & 0.5 & $1888 \pm 2.1$ & $1924 \pm 2.3$ & $1461 \pm 4.1$ & $1167 \pm 2.4$ & $1132 \pm 0.7$ & & \\
\hline $\mathrm{F} 2$ & 1.0 & $1956 \pm 3.4$ & $1983 \pm 1.9$ & $1573 \pm 3.4$ & $1262 \pm 2.7$ & $1232 \pm 0.3$ & & \\
\hline $\mathrm{F} 3$ & 1.5 & $2231 \pm 4.5$ & $2293 \pm 1.3$ & $1632 \pm 2.0$ & $1272 \pm 2.1$ & $1242 \pm 1.8$ & & \\
\hline $\mathrm{F} 4$ & 2.0 & $2325 \pm 1.2$ & $2382 \pm 0.4$ & $2412 \pm 1.1$ & $1312 \pm 1.8$ & $1302 \pm 0.5$ & & \\
\hline F5 & 2.5 & $2493 \pm 3.5$ & $2525 \pm 0.5$ & $2522 \pm 0.5$ & $1342 \pm 0.4$ & $1313 \pm 0.5$ & & \\
\hline F6 & 3.0 & $2574 \pm 4.2$ & $2721 \pm 0.3$ & $2602 \pm 0.2$ & $2154 \pm 0.1$ & $1332 \pm 1.4$ & & \\
\hline F7 & 3.5 & $2772 \pm 1.2$ & $2821 \pm 0.6$ & $2741 \pm 1.2$ & $2363 \pm 0.1$ & $2036 \pm 1.2$ & & \\
\hline F8 & 4.0 & $2757 \pm 1.3$ & $2892 \pm 1.0$ & $2863 \pm 0.4$ & $2402 \pm 1.0$ & $2252 \pm 1.9$ & & \\
\hline F9 & 4.5 & $2951 \pm 2.3$ & $3021 \pm 1.5$ & $2892 \pm 0.3$ & $2483 \pm 1.4$ & $2405 \pm 0.7$ & & tit \\
\hline F10 & 5.0 & $7582 \pm 0.5$ & $8653 \pm 2.3$ & $5902 \pm 0.4$ & $4525 \pm 1.7$ & $2459 \pm 0.4$ & & \\
\hline F11 & 5.5 & $8732 \pm 0.7$ & $8821 \pm 1.9$ & $4962 \pm 0.1$ & $4571 \pm 0.2$ & $3485 \pm 1.6$ & & \\
\hline F12 & 6.0 & $5632 \pm 1.2$ & $5710 \pm 0.6$ & $4054 \pm 2.1$ & $4002 \pm 0.7$ & $2573 \pm 1.7$ & & \\
\hline F13 & 6.5 & $4432 \pm 1.5$ & $4402 \pm 0.3$ & $3096 \pm 0.8$ & $3053 \pm 0.9$ & $2284 \pm 0.3$ & & \\
\hline F14 & 7.0 & $4401 \pm 0.8$ & $4053 \pm 2.4$ & $2963 \pm 0.4$ & $2982 \pm 0.6$ & $1923 \pm 0.7$ & & \\
\hline F15 & 7.5 & $2932 \pm 1.6$ & $3011 \pm 1.8$ & $2206 \pm 0.2$ & $2043 \pm 0.3$ & $1063 \pm 0.3$ & & \\
\hline F16 & 8.0 & $2094 \pm 1.4$ & $2862 \pm 1.1$ & $1863 \pm 2$ & $1303 \pm 0.8$ & $1009 \pm 1.6$ & & \\
\hline F17 & 8.5 & $2071 \pm 2.3$ & $2311 \pm 1.7$ & $1703 \pm 0.6$ & $1034 \pm 0.2$ & $926 \pm 1.4$ & & \\
\hline F18 & 9.0 & $2060 \pm 1.4$ & $2193 \pm 0.1$ & $1642 \pm 1$ & $1093 \pm 0.7$ & $871 \pm 1.2$ & & \\
\hline
\end{tabular}

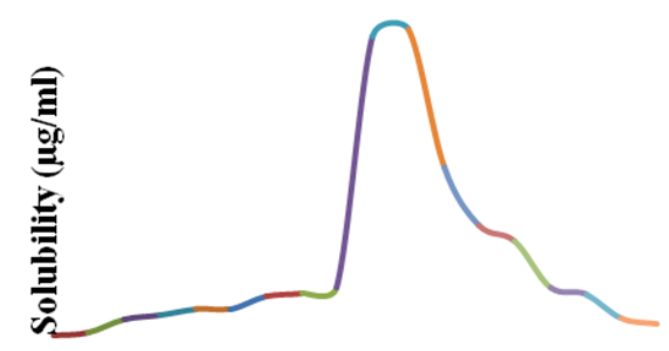

Tween $80(\%$ w/v)

Figure 1. Effect of Tween 80 concentration on the solubility of Piperine at pH 3.0. 
3.2. Determination of CMC of Polysorbate 80.

CMC of polysorbate 80 was determined and shown in table 5.

Table 5. Determination of CMC of Polysorbate 80 and phospholipid.

\begin{tabular}{c|c|c}
\hline \multirow{2}{*}{ Formulation } & \multicolumn{2}{|c}{ CMC } \\
\cline { 2 - 3 } & Polysorbate 80 & Phospholipid \\
\hline F1 & 59.708 & 66.014 \\
\hline F2 & 58.0167 & 63.288 \\
\hline F3 & 62.4414 & 83.1122 \\
\hline F4 & 57.4882 & 63.2264 \\
\hline F5 & 54.2887 & 63.0104 \\
\hline
\end{tabular}

In a study, surfactants were investigated in aqueous media for regular micelles formation. Conventional surfactants have a high critical micelle concentration (CMC). CMC means a concentration beyond which surfactants form micelles. CMC of phospholipid was determined and shown in table 5.

\subsection{Solubility estimation.}

Themaximum solubility of phospholipid was found to be 11.3057 (F3). The solubility of phospholipid is summarized in table 6 .

Table 6. Solubility estimation of phospholipid.

\begin{tabular}{c|c} 
Formulation & Solubility $(\mathbf{m g} / \mathbf{m l})$ \\
\hline F1 & $3.5075 \mathrm{mg} / \mathrm{ml}$ \\
\hline F2 & $6.071 \mathrm{mg} / \mathrm{ml}$ \\
\hline F3 & $11.3057 \mathrm{mg} / \mathrm{ml}$ \\
\hline F4 & $10.3075 \mathrm{mg} / \mathrm{ml}$ \\
\hline F5 & $10.9206 \mathrm{mg} / \mathrm{ml}$
\end{tabular}

\subsection{Entrapment Efficiency.}

The maximum entrapment of phospholipid (table 7) was determined to be $45.23 \%$ (F3) and the minimum entrapment of phospholipid was determined to be $14.03 \%$ (F1).

Table 7. Entrapment efficiency of phospholipid.

\begin{tabular}{c|c} 
Formulation & Entrapment Efficiency (\%) \\
\hline F1 & 14.03 \\
\hline F2 & 29.07 \\
\hline F3 & 45.23 \\
\hline F4 & 41.23 \\
\hline F5 & 42.01
\end{tabular}

\subsection{Evaluation parameter of formulation batches.}

\subsubsection{Entrapment Efficiency and drug content of nanoformulations.}

For the calculation of entrapment efficiency (\%), the absorbance of different formulations was analyzed and concentrations were calculated using the calibration plot of the drug. Entrapment efficiency and drug content of optimized nanoformulations were summarized in table 8 .

Table 8. Entrapment efficiency and drug content of optimized nanoformulations.

\begin{tabular}{c|c|c} 
Formulation & Entrapment Efficiency (\%) & Drug content (mg) \\
\hline F1 & 84.53 & 1.547 \\
\hline F2 & 84.18 & 1.582 \\
\hline F3 & 81.48 & 1.852
\end{tabular}




\subsubsection{Drug Release.}

Drug release $(\%)$ of the formulation was determined by using a rotating Basket of dissolution apparatus and result is mentioned as table 9 while figure 2 reperesents the drug release data of optimized nanoformulation. The drug release was determined in $0.1 \mathrm{~N} \mathrm{HCl}$ at 5, 10, 15, 30 and $60 \mathrm{~min}$. Further, $7.4 \mathrm{pH}$ phosphate was added and release was determined at $30,60,120,180$ and $240 \mathrm{~min}$. $5 \mathrm{ml}$ of the sample was withdrawn at a particular time interval. Samples were analyzed under UV at $231 \mathrm{~nm}$ of $0.1 \mathrm{~N} \mathrm{HCl}$ and phosphate buffer $\mathrm{pH}$ 7.4.

Table 9. Drug release (\%) of optimized nanoformulations.

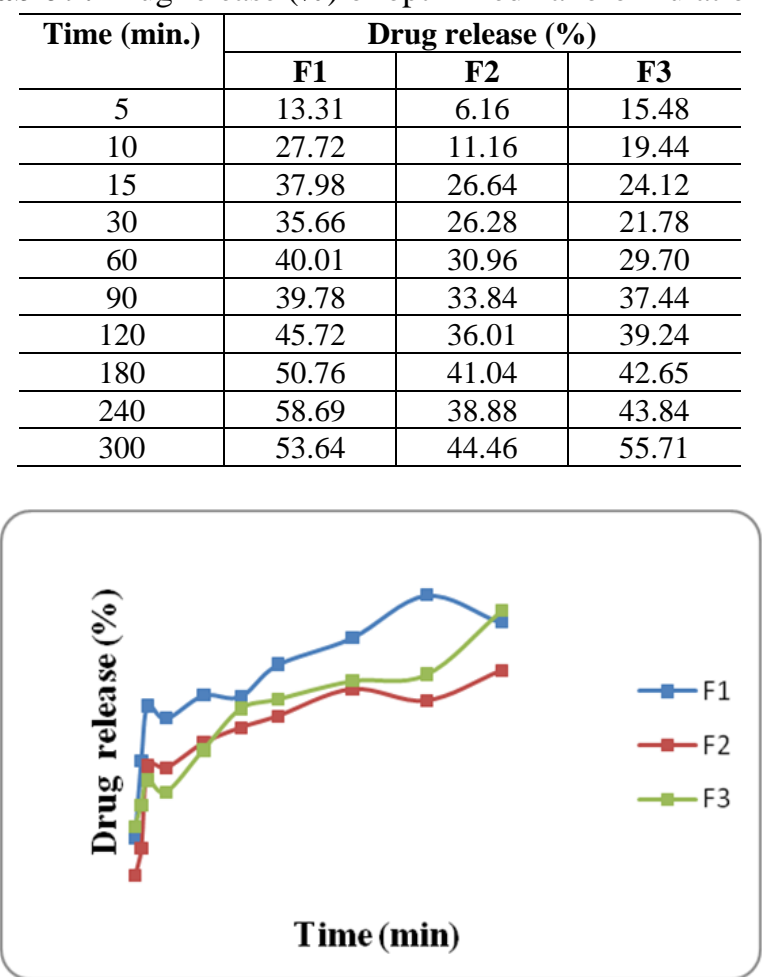

Figure 2. Drug release data of optimized nanoformulation.

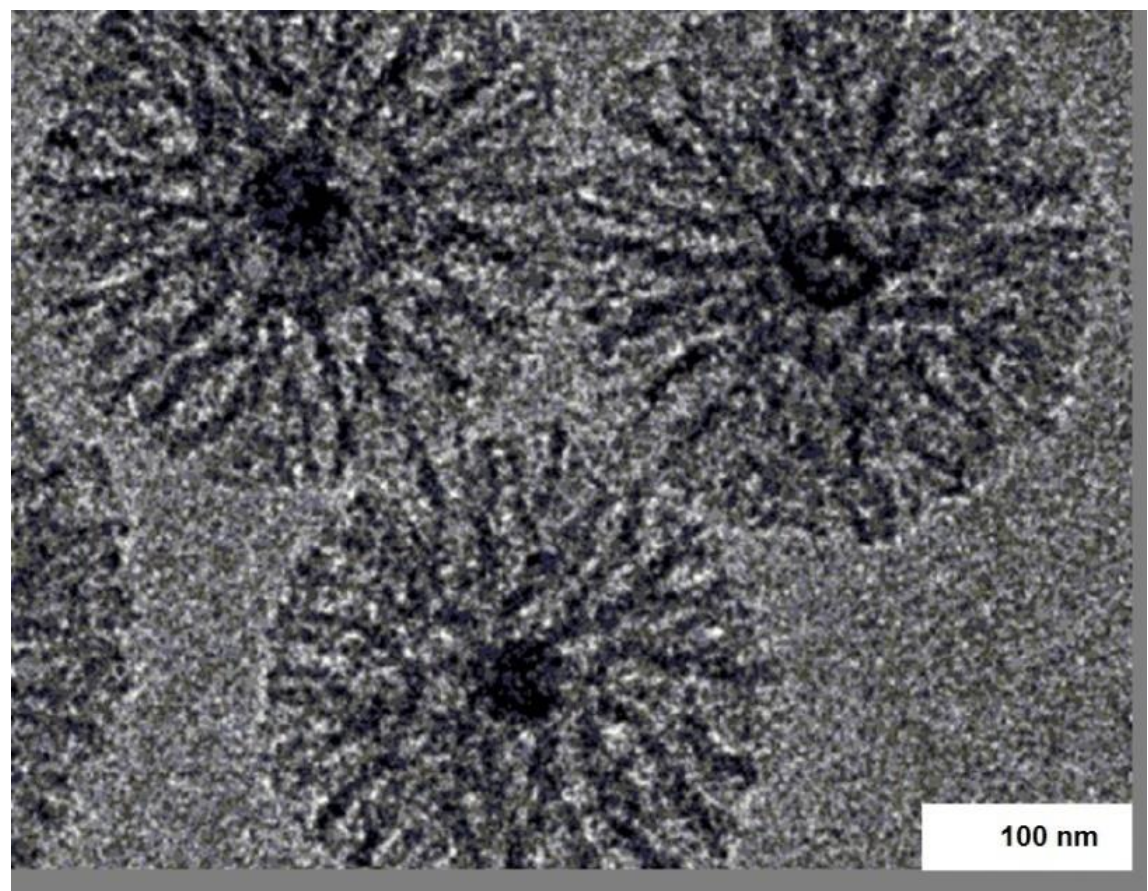

Figure 3. TEM analysis of nanoformulations (F1). 


\subsubsection{Particle size analysis.}

It was determined by using zeta analyzer. The size of the nanoformulations (F1) was found to be $0.3396 \mathrm{rnm}$.

\subsubsection{TEM Antibacterial activity.}

Electrons are accelerated at several hundred $\mathrm{KV}$, resulting in wavelengths much smaller than that of light, and are focused with electromagnetic lenses for imaging. Figure 3 shows the TEM image of nanoformulation N1.

\subsubsection{Antibacterial activity.}

The antibacterial action of nanoformulations was shown visually. Two concentrations viz. $50 \mathrm{mg} / \mathrm{ml}$ and $100 \mathrm{mg} / \mathrm{ml}$ of formulation F1was taken and the antimicrobial effect was determined. Figure 4 shows the antimicrobial effect of F1 against E. coli.

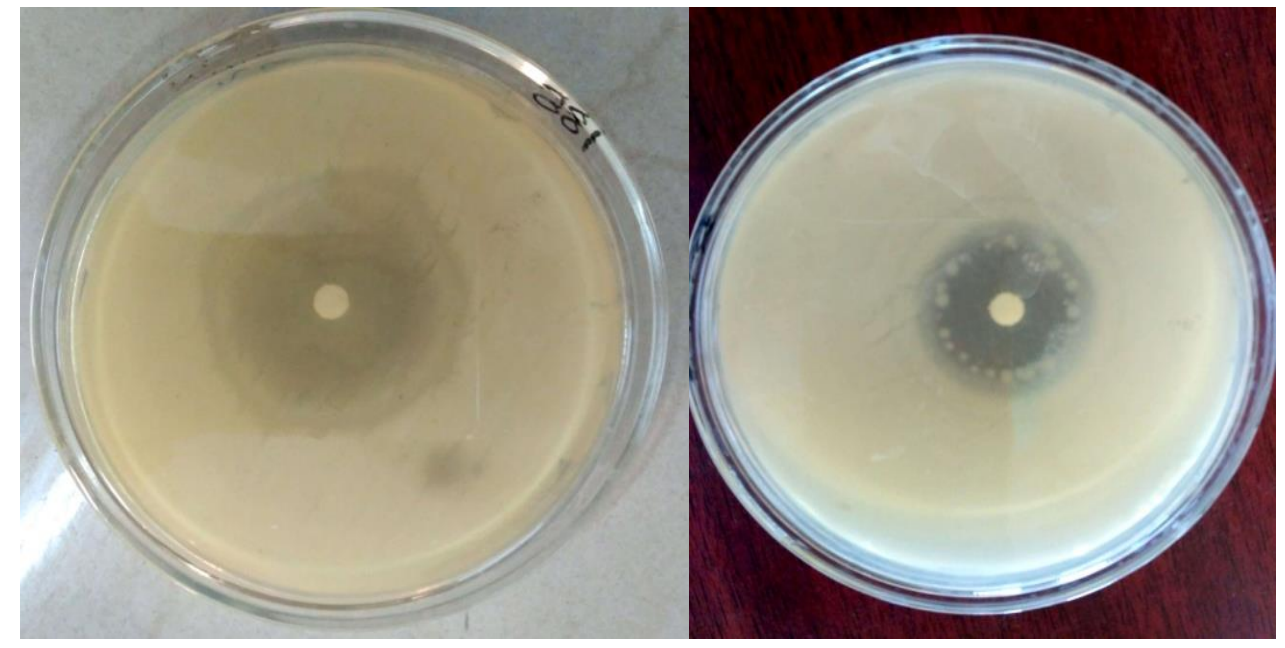

Figure 4. Zone of inhibition study at (a) $100 \mathrm{mg} / \mathrm{ml}$ and (b) $50 \mathrm{mg} / \mathrm{ml}$ concentration of F1.

\section{Conclusions}

Temperature independent stability allowed the storage of drugs at ambient condition but poor solubility could lead to problematic distribution so enhancement in solubility should be considered before designing and developing a formulation. Among different formulation, the maximum solubilized concentration was observed at $\mathrm{pH} 3$. Polysorbate 80 concentrations at $5.5 \% \mathrm{w} / \mathrm{v}$ showed the maximum solubility of piperine which was just similar to $5.0 \% \mathrm{w} / \mathrm{v}$ CMC value so, from such studies, it was confirmed that optimum concentration of polysorbate 80 required for maximum solubilization of piperine was $5.5 \% \mathrm{w} / \mathrm{v}$. It was concluded that batch F3 has maximum CMC, solubility and entrapment efficiency of phospholipid.

Particle size analysis of nanoformulations was done by using zeta analyzer. The particle sizes of the nanoformulations were determined by using zeta analyzer or zeta sizer. $1 \%$ solution of the formulation was employed for the zeta analysis. The size of the formulation was found to be. TEM involves freezing biological material quickly in vitreous ice and imaging at temperatures less than $-180^{\circ} \mathrm{C}$.

Based on the optimization of phospholipid and polysorbate 80 , three final batches were selected as the best batch i.e. F2, F3, and F4 (1:10:4, 1:15:4 and 1:20:4 respectively) for final formulation. It was noted that formulation F4 has maximum drug content $(1.852 \mu \mathrm{g} / \mathrm{ml})$ and F2 
was found as maximum entrapment efficiency i.e. 84.53 . The maximum drug release $(61.03 \%)$ was found in the formulation F3 after $6 \mathrm{~h}$.

The approach of using phospholipid nanoformulations loaded with azithromycin showed antibacterial activity in a nutrient agar plate. These formulations prevent the visual growth of bacteria. It was shown that the maximum zone of inhibition was found at the concentration of $100 \mathrm{mg} / \mathrm{ml}$. The MIC endpoint at the lowest concentration of formulation at which there is minimum visual growth around the dice was found to be $50 \mathrm{mg} / \mathrm{ml}$.

\section{Funding}

This research received no external funding.

\section{Acknowledgments}

Authors are highly thankful to the Department of Pharmacy, School of Medical and Allied Sciences, Galgotias University Greater Noida for providing laboratory facilities.

\section{Conflicts of Interest}

The authors declare no conflict of interest.

\section{References}

1. Ekladious, I.; Colson, Y.L.; Grinstaff, M.W. Polymer-drug conjugate therapeutics: advances, insights and prospects. Nat Rev Drug Discov 2019, 18(4), 273-294. https://doi.org/10.1038/s41573-018-0005-0

2. Banker, G.S.; Siepmann, J.; Rhodes, C. Dosage forms for personalize medicine. Modern pharmaceutics 2013, 5 , 498-555. https://www.taylorfrancis.com/books/e/9780429164279/chapters/10.1201/9780824744694-9

3. Rosenberg, M.F.; Kamis, A.B.; Callaghan, R.; Higgins, C.F.; Ford, R.C. Three-dimensional structures of the mammalian multidrug resistance P-glycoprotein demonstrate major conformational changes in the transmembrane domains upon nucleotide binding. $J$ Biol Chem 2003, 278, 8294-8299. https://doi.org/10.1074/jbc.M211758200

4. Venter, J.C.; Adams, M.D.; Myers, E.W.; Li, P.W.; Mural, R.J.; Sutton, G.G. The sequence of the human genome. Science 2001, 291, 1304-1351. https://doi.org/10.1126/science.1058040.

5. Tombline, G.; Bartholomew, L.; Gimi, K.; Tyndall, G.A, Senior, A.E. Synergy between conserved ABC signature Ser residues in P-glycoprotein catalysis. $J$ Biol Chem 2004, 279, 5363-5373. https://doi.org/10.1074/jbc.m311964200

6. Zhou, T.; Arya, V.; Zhang, L. Comparing Various In Vitro Prediction Methods to Assess the Potential of a Drug to Inhibit P-glycoprotein (P-gp) Transporter In Vivo. J Clin Pharmacol 2019, 59(8), 1049-1060. https://doi.org/10.1002/jcph.1413

7. Bhutani, M.K.; Bishnoi, M.; Kulkarni, S.K. Anti-depressant Like Effect of Curcumin and Its Combination With Piperine in Unpredictable Chronic Stress-Induced Behavioral, Biochemical and Neurochemical Changes.Pharmacol.Biochem Behav 2009, 92, 39-43. https://doi.org/10.1016/j.pbb.2008.10.007

8. Kumari, K.; Sharma, P.K.; Gupta, R. Polysorbate-Phospholipid Complex Micelles as P-glycoprotein Inhibitor Drug Delivery System. J Basic Pharmacol Toxicol 2017, 1, 2-7. http://scigreen.com/index.php/JBPT/article/view/8

9. Jin, M.; Liao, C.; Chakrabarty, S.; Zheng, W.; Wu, K.; Xiao, Y. Transcriptional response of ATP-binding cassette (ABC) transporters to insecticides in the cotton bollworm, Helicoverpa armigera. Pestic Biochem Phys 2019, 154, 46-59. https://doi.org/10.1016/j.pestbp.2018.12.007

10. Orelle, C.; Mathieu, K.; Jault, J.M. Multidrug ABC transporters in bacteria. Res Microbiol 2019, 170(8), 381-391. https://doi.org/10.1016/j.resmic.2019.06.001 